\title{
INADIMPLÊNCIA NO SISTEMA FINANCEIRO DE HABITAÇÃO: UM ESTUDO JUNTO À CAIXA ECONÔMICA FEDERAL (CAIXA)
}

DEFAULT IN DWELLING FINANCIAL SYSTEM: A STUDY WITH CAIXA ECONÔMICA FEDERAL - CAIXA (FEDERAL SAVING BANK)

CARLOS FERTANDO SEHIN

Faculdade Boa Viagem (FBV)/Gestão de Negócios/Espaço Executivo II. Rua Dona Balbina Menelau, 15, apto. 1.002 - Jaboatão dos Guararapes - PE - CEP 54440-615 E-mail: carlos.sehn@bol.com.br

REGINALDO JOSÉ CARLINI JUNIOR

Professor da Faculdade Boa Viagem (FBV)/Espaço Executivo II. Av. Dr. José Augusto Moreira, 1.330, apto- 203 - Olinda - PE - CEP $53130-410$ E-mail: naldocarlini@yahoo.com.br 


\section{RESUMO}

A inadimplência, hoje, é um dos fatores que mais preocupam as empresas, independentemente do seu tamanho ou faturamento. Mais do que vender, elas devem se preocupar em como e quando receber para garantir a sua sobrevivência. Este trabalho tem como objetivo compreender o grau de importância dado pelos mutuários da Caixa Econômica Federal (Caixa) no que se refere à inadimplência habitacional no Estado de Pernambuco. É importante destacar que foram aplicados questionários a mutuários inadimplentes dessa empresa, localizados na capital e no interior do Estado de Pernambuco. Os resultados obtidos demonstraram que houve uma pequena queda na inadimplência após a implantação do Sistema de Risco de Crédito (Siric), a partir de 2000 , mas que, de acordo com os índices atuais e com os resultados da pesquisa, os esforços precisam ser redobrados para que os índices caiam a níveis aceitáveis.

\section{PALAVRAS-CHAVE}

Inadimplência; Habitacional; Risco de crédito.

\section{ABSTRACT}

Default is one of the main factors bringing great concern to companies today, regardless of their size or invoicing. More than selling, they are concerned about how and when they will receive to assure their own survival. This work has for objective to understand the degree of significance given by borrowers of Caixa Econômica Federal (Caixa) in respect of dwelling default in the State of Pernambuco. It should be pointed out that questionnaires have been answered by defaulting borrowers of this company, located both in the capital and inland of the State of Pernambuco. Results achieved have shown that a small decrease in default was noted from the implementation of the Credit 
Risk System (Siric), from 2000; however, according to the current indexes and research results, efforts have to be intensified to make indexes fall into acceptable levels.

\section{KEYWORDS}

Default; Dwelling; Credit risk.

\section{INTRODUÇ $\tilde{A} O$}

A palavra crédito deriva do latim credere, que significa acreditar, confiar, ou seja, uma pessoa põe crédito e confiança em seus compromissos com a outra.

Ninguém confia em desconhecidos, em pessoa que acabou de conhecer ou em alguém de quem se tem poucas informações. Para que se confie em pessoas, é fundamental conhecê-las e, para isso, necessita-se basicamente de tempo e informação.

No mundo profissional, as decisões de crédito não envolvem essencialmente pessoas conhecidas, nem os empréstimos são gratuitos. O risco, sempre presente em qualquer empréstimo, coloca-se de forma mais visível, e sua avaliação tornase uma tarefa extremamente importante para análise e julgamento do crédito.

A política de crédito de uma empresa é um assunto de extrema importância para o seu concessor, pois fornece instrumentos que auxiliam na hora da decisão de confiar, acreditar ou não, funcionando como orientadores da concessão.

A gestão do risco de crédito resume-se em aprovação de empréstimos mediante informações a respeito do cliente e concessão apenas àqueles que se situem dentro de limites favoráveis de risco, determinados pela política de crédito da empresa.

Desde a implementação do Plano Real em I994, passa-se a conviver com uma elevação do índice de inadimplência em todos os setores da economia nacional. A população, acostumada a conviver com altos índices de inflação, começa a conviver com uma economia estável, com inflação abaixo de $20 \%$ ao ano, segundo dados do Instituto Brasileiro de Geografia e Estatística (IBGE). As pessoas passam a ter que se adaptar à nova realidade: não existem mais os reajustes mensais de salário, nem as aplicações de over night e open market, com rendimento diário e que protegiam os salários da inflação. Diante dessa nova realidade econômica, a sociedade brasileira teve que conviver com um salário sem as alterações mensais indexadas pela inflação e passou a contar com um 
orçamento doméstico fixo, sem a ilusão da inflação e com despesas que, teoricamente, deveriam ser totalmente pagas com esse rendimento.

Foi a partir dessa época que se institucionalizou a inadimplência no Brasil. O Banco Central (BC) criou normas de renegociação de dívidas, privilegiando prazos e taxas, em razão da crise que se instalou pela falta de pagamento nos mais diversos ramos de atividades públicas e privadas, como escolas, lojas comerciais e bancos.

A Caixa Econômica Federal, em 200I, vendeu parte de seus contratos habitacionais ativos, que apresentavam desequilíbrio financeiro, para a Empresa Gestora de Ativos (Emgea), que ficou responsável por esses chamados “créditos podres", livrando a Caixa de vários anos de balanços negativos. Vale ressaltar que esses eram contratos inadimplentes e cujos créditos a eles inerentes eram inferiores ao custo de sua administração, em razão do descompasso entre saldo devedor e prestação, gerando resíduo a pagar no final do prazo. Mas, apesar de ter ficado somente com contratos "equilibrados" em seu patrimônio, a inadimplência habitacional continua alta, correspondendo atualmente a aproximadamente I4\%, o equivalente a cerca de 420 mil famílias que não conseguem pagar em dia suas prestações (CAIXA ECÔNOMICA FEDERAL, 2004).

Diante desse quadro, verificar as causas dessa alta inadimplência e desse descontrole torna-se necessário. É importante verificar a influência que o Sistema de Risco de Crédito (Siric) da Caixa pôde exercer nas novas concessões a fim de evitar que novos empréstimos sejam concedidos sem a garantia de retorno financeiro, o que poderia acabar prejudicando o restante da população, que busca o empréstimo habitacional como única alternativa de conquistar a casa própria.

\section{FUNDAMENTAÇÃO TEÓRICA}

\subsection{A INADIMPLÊNCIA E SUAS CAUSAS}

Inadimplência é a falta de pagamento ou o não-cumprimento de um contrato ou cláusula. Pode significar a não-satisfação daquilo a que se está obrigado ou do prazo que está sendo predeterminado. Em outras palavras, inadimplência é o não-pagamento da dívida. O artigo 580 do Código de Processo Civil brasileiro preceitua sobre o inadimplemento, considerando como inadimplente o devedor que não satisfaz espontaneamente o direito reconhecido pela sentença ou a obrigação que a lei atribuir à eficácia de título executivo. 
A primeira renegociação de dívida de um contrato inadimplente que se tem notícia no Brasil ocorreu em I898, tendo como protagonista o Estado. Rocha (1997, p. I2) afirma que "data de I5 de junho de 1898 a assinatura da primeira renegociação de dívidas não pagas entre a República do Brasil e seus credores externos [...]".

Essa situação não mudou com o tempo, pois vêem-se até hoje constantes deslocamentos de ministros ao exterior buscando repactuar contratos da nossa dívida externa ou aumentando metas de superávit fiscal, que é a economia interna feita para pagar os juros dessa dívida.

Analisar as causas da inadimplência de um contrato é um fator de extrema importância na resolução e na tomada de decisões sobre o caso.

Gitman (2002) afirma que a principal causa da inadimplência é a má administração do contrato, a qual é responsável por mais de 50\% de todos os casos. Essa má administração compreende uma expansão excessiva, medidas financeiras inadequadas, uma força de vendas insuficiente e altos custos de produção.

Para Blatt (I998, p. 24), existem várias causas que levam à inadimplência, entre elas:

Critérios agressivos de concessão de crédito; este comportamento permite aos analistas tornarem-se mais negligentes no critério de créditos; política de crédito e procedimentos mal-implementada e mal monitorada; negligência para uma avaliação correta, documentos e garantias, contato não freqüente com o cliente, com raras visitas; relutância em admitir um engano de análise de crédito ou em reconhecê-lo como um problema efetivo, análise de crédito fraca, cliente fora dos objetivos da empresa, tratamento de problemas a longo prazo com soluções de curto prazo.

Os analistas de crédito devem ser rigorosos quanto à avaliação da operação que estão aprovando, procurando detalhes técnicos que levem a concessão a ser cercada de toda a segurança possível, evitando futuros inadimplentes.

Segundo Silva (I997, p. 373), as prováveis causas que originam um crédito problemático são:

Erros por parte do credor; fraca entrevista de empréstimo, análise financeira inadequada, utilização apenas do feeling, suporte inadequado ao empréstimo, documentação exigida inadequada, interferências políticas, frágil investigação do crédito, gerenciamento inadequado, equipe despreparada e estrutura de crédito mal definida. 
Devem-se exigir do cliente todos os documentos necessários para fazer um bom cadastro, uma entrevista de qualidade, verificar pontualidade de pagamento em outras empresas e, o mais importante, dispor de um sistema de risco eficiente que auxilie na concessão.

Para Rocha (I997, p. 90), as causas mais freqüentes ao analisar um crédito inadimplido são:

[...] negligência do concessor; gerentes com medo do cliente que xinga pela demora do crédito e gerente que fecha grandes negócios num piscar de olhos, estes, normalmente, têm pouco conhecimento do cliente; padrinhos políticos e falta de uma política de créditos.

Deve-se ter cuidado, ao conceder um crédito, de não se deixar levar por pressões internas e externas. Metas são estipuladas e devem ser cumpridas, mas não sob intenso risco e sem tomar as devidas informações e precauções sobre o cliente.

De acordo com a Câmara dos Dirigentes Lojistas (CD) de Juiz de Fora - MG, as pessoas não deixam de pagar suas dívidas porque querem, e sim por alguma situação inesperada, como perda do emprego, problemas na família, doenças e empréstimo de cheques. Com relação a esse último, a TeleCheque - empresa que reúne um dos maiores bancos de dados sobre inadimplência no País - diz que emprestar folhas de cheque para parentes e amigos fazerem compras é uma prática mais comum do que se imagina, e um dos principais motivos que levam à inadimplência.

\subsection{A INADIMPLÊNCIA NO SISTEMA FINANCEIRO DA HABITAÇÃO (SFH)}

Por meio da Lei n. 4.357/64 de I964, é criado o Sistema Financeiro Nacional (SFN), e em agosto do mesmo ano, pela Lei n. 4.380, surge o Sistema Financeiro da Habitação (SFH) e com ele o Banco Nacional da Habitação (BNH). Vale ressaltar que esse exerceria um papel importante na legislação, fiscalização e implementação de uma política habitacional para o País, por meio do encadeamento de ações estratégicas e instituições de alternativas financeiras voltadas para a canalização da poupança interna em financiamentos para a produção e comercialização de unidades habitacionais.

Analisando tecnicamente, pode-se observar que o SFH foi um modelo extremamente bem concebido, principalmente por propiciar crédito habitacional a mais de seis milhões de brasileiros, salientando que esse desempenho foi conseguido na primeira metade da sua existência. 
[...] o SFH foi um sistema eficiente, que, enquanto manteve as fontes de recursos e as condições de retorno equilibradas, cumpriu o seu papel, embora, posteriormente, em função do mau gerenciamento e de intervenções equivocadas por parte do governo, tenha sido totalmente mutilado e exaurido na sua capacidade de operar [...] (MARTINS, I998, p. I6).

Em meados da década de I980, o SFH passou a viver crises complexas e sucessivas, justificadas prioritariamente pela deterioração da economia nacional. Uma parte da população ficou sem seus empregos e experimentava, progressivamente, as dificuldades de arcar com o pagamento das prestações dos financiamentos habitacionais.

A sucessão de choques heterodoxos na economia e políticas monetárias restritivas desorganizou e influenciou substancialmente a política habitacional vigente, limitando de forma efetiva o acesso ao crédito imobiliário. Isso prejudicou toda uma cadeia composta por indústria da construção civil, mutuários, agentes financeiros e, conseqüentemente, postulantes a uma linha de crédito habitacional, provocando uma maximização no déficit habitacional brasileiro (MORAIS, 200I).

O modelo inovador dos anos I960, concebido por um sistema baseado em duas grandes fontes de recursos, a caderneta de poupança e o Fundo de Garantia por Tempo de Serviço (FGTS), além dos instrumentos de estabilização ante as oscilações da economia, a exemplo do Fundo de Compensação das Variações Salariais (FCVS), do Coeficiente de Equiparação Salarial (CES) e do Fundo para Pagamento de Prestações no Caso de Desemprego e Invalidez Temporária (FIEL), acabou transformando-se em um sistema ineficiente cuja falência foi perceptível, justificado por uma seqüência de políticas malsucedidas que provocaram a deterioração do sistema, atingindo seus principais pilares, a retroalimentação, retorno do capital investido, prejudicando sua auto-sustentabilidade.

Os choques provocados pelos diversos planos econômicos, mesmo com todas as medidas adotadas para socorrer e teoricamente garantir um retorno ao sistema, não estancaram o quadro da inadimplência.

O fenômeno da inadimplência contaminou todo o sistema, prejudicou o retorno do capital investido e, conseqüentemente, impediu a concessão de novos financiamentos.

Em I985, as prestações dos contratos habitacionais regidos pelo Plano de Equivalência Salarial por Categoria Profissional (PES/CP), por força de dispositivos legais, contaram com reajuste de II $2 \%$ em detrimento de $246 \%$ que foi a real variação do período (CAIXA ECONÔMICA FEDERAL, 2004).

Em I986, a economia brasileira viveu sob a égide do Plano Cruzado, que adotou o mecanismo de conversão da moeda. Para o cálculo das prestações habi- 
tacionais, considerou a média das I2 últimas prestações, desprezando o histórico do contrato. Depois de adotado esse mecanismo, implementou-se o congelamento das prestações por mais I2 meses.

No ano seguinte, I987, o Brasil viveu o Plano Bresser, que adotou a conversão das prestações habitacionais pela Unidade de Referência de Preços (URP). Um novo congelamento das prestações é trazido em I990 por força de um novo choque na economia, o Plano Collor.

Essas ocorrências, dentre outras, causaram impacto frontal ao desenvolvimento dos contratos habitacionais e, conseqüentemente, à vida dos seus titulares, principalmente por elas terem gerado saldos devedores consideráveis, desequilibrando financeiramente os contratos e, em várias situações, com o agravante de o valor de mercado do imóvel ser bem inferior ao da sua dívida junto aos agentes financeiros.

Configurando ainda mais o estado de coma do SFH, observa-se um vagaroso comportamento do Judiciário em prolatar decisões referentes às ações que reclamam e questionam algum direito proveniente de questões envolvidas nas diversas modalidades dos contratos de financiamentos imobiliários. Todavia, tal comportamento é interpretado por muitos como uma forma de decidir, ante as hipercomplexidades que envolvem a matéria, consubstanciando ainda mais o grande desafio na gestão e concepção de uma adequada política habitacional para o País.

O SFH foi estruturado para a garantir rentabilidade e liquidez dos depósitos a cada 30 dias, com correção monetária plena, e de outra parte exercer a função econômica de aplicar esses recursos sob taxas tabeladas em prazo médio de I5 anos. Esse fato gera um descompasso entre o prazo dos recursos captados e o prazo em que os estes são aplicados. O que se busca constantemente é conciliar as duas funções, de forma que mantenha o equilíbrio do sistema, capacitando a sua operação contínua em créditos habitacionais. A preservação da compatibilidade desses fluxos, para a instituição de que se captam e aplicam os recursos no mercado, garante a manutenção e vitalidade do sistema.

Compatibilizar indexadores e mecanismos que mantenham a capacidade de pagamento dos financiamentos concedidos, uma diversificação do portfólio de aplicações e o combate à inadimplência são condições essenciais para se ter o equilíbrio dos contratos e para manter a distribuição de recursos no setor habitacional.

Para que esse ciclo captar-emprestar-receber continue a acontecer, torna-se necessário o retorno dos recursos emprestados, sob a forma de pagamentos de suas prestações. Segundo Silva (I997), tal situação nada mais é do que a promessa de pagamento do devedor, pois a certeza do recebimento o credor irá verificar no momento em que o débito for honrado. 
Pela assinatura do contrato mútuo de capital (empréstimo de dinheiro), o devedor assume deveres, mas também tem certos direitos, entre eles: seguro em caso de Morte e Invalidez Permanente (MIP) ou de Danos Físicos do Imóvel (DFI), em que se tem a cobertura em caso de danos causados por fatores externos, como chuva, vendaval e incêndio. Do lado dos deveres, está o pagamento em dia das suas prestações, sob pena de seu nome ser incluído nos cadastros restritivos de crédito, como o Serviço de Proteção ao Crédito (SPC), Sistema de Inadimplentes (Sinad) (interno da Caixa) e o Serasa, ou até mesmo perder a propriedade do imóvel por meio da sua execução, já que nos contratos habitacionais a garantia dominante é a hipoteca, que é baseada na entrega do bem imóvel para o credor, caso não se cumpram suas obrigações contratuais.

\subsection{FORMAS DE EVITAR A INADIMPLÊNCIA}

A maneira mais eficaz de evitar a inadimplência de um contrato é conceder bem, ou seja, dar crédito a quem realmente mostra ter condições de assumir o compromisso. Isso não é tarefa fácil num país que ainda luta para conseguir sua estabilidade econômica e constantemente passa por turbulências, afetando pessoas que assumem compromissos de longo prazo como os empréstimos habitacionais.

Em muitos casos, a inadimplência poderia ser evitada, se, no momento da concessão, fossem tomados alguns cuidados, tais como:

- Atualização das informações cadastrais;

- Preenchimento correto e completo do cadastro, com dados que espelhem a situação econômica, financeira e patrimonial do cliente;

- Percepção da demanda existente no mercado, com o intuito de evitar oferecer quantitativo excessivo de crédito para um mesmo tomador;

- Entendimento de que verificar a situação cadastral do cliente vai além das pesquisas fundamentais nos cadastros de crédito, como SPC, Serasa e BC, e inclui informações sobre histórico de crédito, hábitos de consumo, relacionamento com outras instituições financeiras, entre outras. Vale registrar que, na pesquisa cadastral atualizada, grande parte dos inadimplentes aparece com pendências junto a mais de uma instituição financeira, o que ressalta a necessidade de verificação do histórico de crédito no ato de emprestar.

Os mecanismos de verificação são instrumentos necessários para automatizar e padronizar procedimentos de análise de risco e concessão de crédito. Po- 
rém, como ferramentas à disposição do concessor, devem ser bem aproveitados, tanto na alimentação de informações de qualidade quanto na utilização dos resultados, já que nem sempre podem ser determinantes do ato de conceder. Os valores por eles autorizados, aplicados em sua totalidade, poderão fragilizar o retorno dos recursos, se observados taxas e prazos, em relação às condições e perspectivas dos tomadores corretamente contextualizados no mercado. Merece destaque o papel do concessor, que precisa adquirir cada vez mais a cultura da investigação cadastral e percepção clara do mercado em que está atuando.

No momento da entrevista, é fundamental conhecer qual é o projeto, ainda que mental, do cliente, ou seja, em que ele vai aplicar o recurso tomado emprestado no banco. Há muitos sonhos que não são realizáveis com recursos de terceiros em razão da falta de indicadores de liquidez. Muitas informações não podem ser convertidas em números que representem valores para alimentar ferramentas de avaliação, mas são ótimos instrumentos de avaliação. O relacionamento informal com o cliente pode subsidiar/influenciar a decisão do concessor.

Se, por um lado, a pulverização do crédito é a tônica empreendida pelas instituições financeiras e se reflete no perfil da amostra de inadimplência avaliada, por outro, garantir a maximização dos retornos é imprescindível, razão pela qual minimizar os riscos se torna um desafio a ser perseguido, para que a inadimplência não neutralize os resultados.

A existência de meta para emprestar, em uma instituição financeira, entende-se ser necessária, porém com atenção a todos os quesitos da conformidade, dos aspectos formais da contratação e, ainda, a preocupação em receber todo o capital emprestado como obrigação.

Outro aspecto observado é de que, após a concessão, um efetivo acompanhamento, que vem sendo implementado por algumas instituições, que inclui lembrete para o tomador antes do vencimento da obrigação e efetivos pontos de controle, fortalece o hábito de pagamento em dia dos tomadores.

Pode-se dizer que evitar a inadimplência é bem menos oneroso que combatê-la. Isso exige qualidade na concessão, que precisa estar pautada em métodos eficazes de análise, que somente terão valia se as informações fornecidas retratarem a fiel realidade socioeconômica do tomador de crédito.

É importante lembrar sempre que, pior do que não emprestar, é não receber; e que as más cobranças são a certeza de maus resultados, e boas cobranças não são a certeza de bons resultados. Vale ressaltar que quanto melhor for estruturada a concessão, maiores serão as chances de seu resgate. 


\section{METODOLOGIA}

A metodologia utilizada neste trabalho teve os seguintes princípios:

- Quanto à forma de abordagem: uma pesquisa quantitativa, pois esta é caracterizada pelo emprego da quantificação tanto nas modalidades de coleta de informações quanto no tratamento delas por meio de técnicas estatísticas, desde as mais simples como porcentual, média e desvio padrão (RICHARDSON, I999).

- Quanto ao tipo de pesquisa: uma pesquisa descritiva: "As pesquisas descritivas têm como objetivo primordial a descrição das características de determinada população ou fenômeno ou, então, o estabelecimento de relações entre variáveis" (GIL, I99I, p. 46).

- Quanto aos procedimentos técnicos: a pesquisa está focada num estudo de caso, definido como o estudo profundo e exaustivo de um ou poucos objetos de maneira que se permita o seu amplo e detalhado conhecimento (GIL, I99I). Este estudo foi apoiado pela análise de documentos produzidos pela Caixa Econômica Federal, como manuais normativos, boletins, gráficos, jornais e outros periódicos da instituição, elaborados e distribuídos por seus técnicos. Também se utilizou como procedimento de coleta de dados a pesquisa bibliográfica, na qual foram consultadas bibliografias disponíveis sobre o assunto. Outro procedimento de coleta de dados utilizado foi o questionário; "O questionário é um instrumento de coleta de dados constituído por uma série ordenada de perguntas, que devem ser respondidas por escrito e sem a presença do entrevistado" (RAMPAZZO, 2002, p. IIo). É importante destacar que se optou por elaborar o questionário composto por perguntas abertas: "Os questionários de perguntas abertas caracterizam-se por questões ou afirmações que levam o entrevistado a responder com frases ou orações" (RICHARDSON, I999, p. I92). Ao responder perguntas abertas, o entrevistado fica livre para explicar sem restrições suas opiniões. Os questionários foram aplicados com mutuários inadimplentes (acima de três prestações em atraso), a sua aplicação contou com o auxílio de uma das empresas de cobrança terceirizada que prestam serviço para a Caixa, a Jorge \& Lima Assessoria e Consultoria Jurídica Ltda. Vale ressaltar que a escolha da Caixa como objeto deste estudo foi motivada por ser ela reconhecidamente o maior agente financeiro na área de habitação do País e pelo fato de a inadimplência, nesse segmento, ser um grande dificultador no retorno dos recursos, em que estão aplicados mais de $70 \%$ dos ativos dessa organização.

- A área de abrangência do estudo foi no âmbito do Estado de Pernambuco, com I83 mutuários inadimplentes da capital e I83 do interior, e teve como 
foco levantar as principais causas da inadimplência desses contratos. Vale ressaltar que a escolha de I83 mutuários da capital e I83 do interior deveu-se ao fato de existirem diferentes índices nesses dois campos de amostra, razão pela qual deva ser investigado em separado. É importante destacar que a área de abrangência da capital refere-se aos inadimplentes localizados na região metropolitana de Recife. Por sua vez, a área de abrangência do interior refere-se aos inadimplentes localizados no município de Caruaru.

Elaboração do cálculo do tamanho da amostra

Fórmula para cálculo amostral de população finita:

$$
N=\frac{Z^{2} \cdot p \cdot q \cdot N}{d^{2}(N-1)+Z^{2} \cdot p \cdot q}
$$

Fonte: Fonseca (1996, p. I79).

onde;

$\mathrm{N}$ = tamanho da amostra;

$\mathrm{Z}^{2}=$ nível de significância. Vale ressaltar que esse nível de significância tem um valor de 3,84I6 com 95\% de nível de confiança;

$\mathrm{d}=$ erro de estimação. Considerou-se para este estudo um valor de $5 \%$;

$\mathrm{p}=$ proporção da característica pesquisada no universo, calculado em porcentagem;

$\mathrm{q}=\mathrm{IOO}-\mathrm{p}$ (em porcentagem).

$$
\begin{aligned}
& =\frac{3,8416 \cdot 50 \cdot 50 \cdot 7256}{25 \cdot(7256-1)+3,8416 \cdot 50 \cdot 50}=\frac{3,8416 \cdot 2500 \cdot 7256}{25 \cdot 7255+3,8416 \cdot 2500}= \\
& =\frac{69686624}{181375+9604}=\frac{69686624}{190979}= \\
& =364,89=365
\end{aligned}
$$

Como foi estabelecido que a pesquisa seria realizada na capital pernambucana e no interior do Estado, a amostra obtida de 365 elementos foi dividida, 
objetivando, assim, encontrar elementos iguais para os espaços geográficos anteriormente descritos. Ao dividir a amostra encontrada, obtém-se um resultado de 182,5 . Vale ressaltar que foi importante o seu arredondamento para encontrar um resultado exato. Sendo assim, aplicaram-se I83 questionários para os mutuários inadimplentes do interior e I83 para os da capital.

\section{ANÁlise dos RESULTAdos}

\subsection{O RISCO DE CRÉDITO NA CAIXA}

As avaliações de risco de crédito na Caixa são feitas pelo Siric, sistema implantado a partir de 2000 , que realiza essas análises com o intuito de mensurar o risco para a concessão de crédito nas áreas comercial e habitacional. Vale ressaltar que também esse sistema avalia riscos para a concessão de cartões de crédito. A avaliação da operação tem a finalidade de apurar o risco envolvido na transação e a garantia oferecida para fins de aprovisionamento do crédito.

Nas avaliações de risco de crédito, são aplicadas as seguintes metodologias:

- Avaliação de perfil - credit score;

- Avaliação comportamental - behaviour score; e

- Avaliação de cadastro e renda.

Na avaliação de risco de crédito para habitação, não há segmentação de cliente, e a metodologia utilizada é unicamente avaliação de perfil - credit score, considerando também o comportamento em outras operações de crédito.

A seguir, apresentam-se os resultados da inadimplência ano a ano, tomando-se por base o ano de 2000 que foi o período da implantação do Siric.

Observa-se que em 2000 tinha-se uma inadimplência variando entre $20 \%$ e $40 \%$, período em que as propostas de financiamento passaram a sujeitar-se à aprovação do Siric; a avaliação antes era muito subjetiva.

De 2000 a 200I, observa-se uma queda entre 7 e Io pontos porcentuais na inadimplência, refletindo a rigidez com que as novas concessões eram processadas e a dificuldade de se conseguir financiamento habitacional na Caixa. Segundo dados da Caixa Econômica Federal (2004), cerca de 50\% dos pedidos de financiamento que chegavam às agências eram rejeitados pelo sistema Siric, o que resultou que apenas io\% do valor disponível para emprestar fosse realmente emprestado. Esse fato fez que a direção da Caixa pedisse revisão dos critérios de 
concessão e procedesse a ajustes no sistema, tornando-o mais flexível. Deve-se ressaltar também que em julho de 200 I houve a cessão de créditos daqueles contratos de difícil recuperação para a Emgea, melhorando, significativamente, o resultado nesse período.

\section{FIGURA I}

\section{GRAFICO COM PORCENTUAIS DE INADIMPLENCIA POR PERIODO}

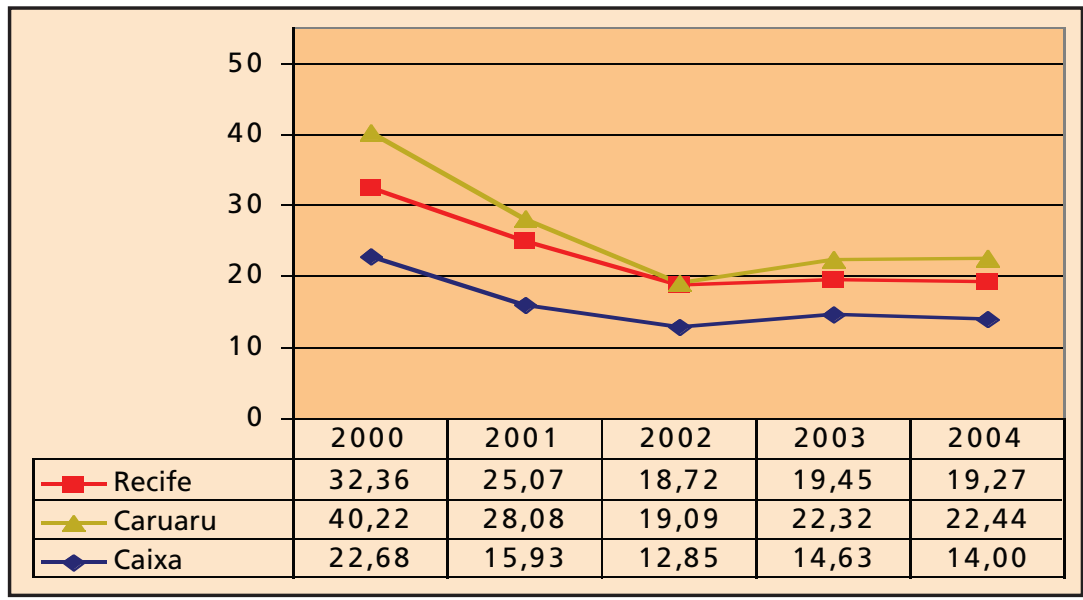

Fonte: Caixa Econômica Federal (2004).

No período 200I-2002, depois de a Caixa ter se livrado dos contratos desequilibrados, é que se nota de fato uma queda acentuada na inadimplência, de $3 \%$ a $7 \%$, dando a real dimensão do que representou o uso do Siric nas concessões. Com os gerentes mais acostumados com o novo sistema, tornou-se mais seguro conceder crédito, pois o critério subjetivo foi eliminado.

Após esse período de queda, houve um pequeno avanço na inadimplência no período de $2002 / 2003$ de cerca de $2 \%$, mantendo a estabilidade no período de $2003 / 2004$.

A análise do gráfico possibilita também chegar a uma conclusão importante: os índices apurados no Estado de Pernambuco estão muito além da média nacional, tanto na capital quanto no interior, em parte isso é justificado pela situação econômica das regiões Sul, Sudeste e parte da Centro-Oeste, onde os índices são menores. Deve-se ressaltar também fatores como falta de infra-estrutura nos 
prédios, problemas estruturais, facilidade com que se conseguia financiamento na época, tudo isso somado a construtoras mal administradas que acabavam falindo. Esses números são ainda maiores no interior, onde o fator político é mais forte, com os chamados currais eleitorais. Esses aspectos colaboraram para que as verbas para habitação fossem mal direcionadas e sem critérios bem definidos. Além disso, deve-se considerar um dado cultural: muitos acreditam que como o financiamento é do governo, não deve ser prioridade no orçamento familiar.

\subsection{A INADIMPLÊNCIA NA CAIXA}

Os crescentes números de inadimplência no SFH fizeram que a Caixa adotasse novas medidas na concessão de financiamentos habitacionais. A partir de I997, a Caixa desenvolveu um sistema de amortização para seus financiamentos na área habitacional, implantando o Sistema de Amortização Crescente (Sacre), que busca um maior equilíbrio no contrato, visto que a prestação no início é maior, ocorrendo uma amortização também maior, gerando a partir do terceiro ou quarto ano, o que dependerá do contrato, uma queda da prestação. O fato negativo, porém, é que não se vinculam mais prestação e salário; quando ocorre perda de renda ou desemprego, a prestação não é recalculada.

Essa foi uma das ações adotadas pela Caixa para tentar reduzir a inadimplência de seus contratos. A outra foi vender parte de seus créditos habitacionais, quase um milhão de contratos, para a Emgea, criada pelo governo em 200I para absorver os contratos classificados como desprezíveis. Vale ressaltar que esses contratos são aqueles cuja inadimplência é muito alta e os custos administrativos são superiores a seus créditos. Esses contratos tiveram vários fatores que os levaram ao desequilíbrio, entre os quais:

- A prestação não poderia subir caso não houvesse aumento salarial do mutuário, o famoso Plano de Equivalência Salarial (PES), e o saldo devedor continuava subindo com base em outros índices, como a Taxa Referencial (TR), o Índice Nacional de Preços ao Consumidor (INPC) e o Índice de Preços ao Consumidor (IPC), gerando ao final do prazo contratual outro valor a pagar tão alto quanto o que foi concedido, ou maior.

- Os diversos planos econômicos (Bresser, Cruzado, Collor) acabaram gerando descompasso no saldo devedor, pois corrigiam os saldos e não as prestações e os salários.

- Alguns dos contratos assinados àquela época contavam com a cobertura do Fundo de Compensação das Variações Salariais (FCVS), que quitava o con- 
trato ao final do prazo, independentemente de ter saldo devedor ou não, gerando um prejuízo muito grande ao Tesouro Nacional, que repassava os valores à Caixa.

Por meio dessas medidas, esperava-se reduzir a inadimplência dos contratos habitacionais, que passaram a contar também com uma avaliação de risco de crédito mais criteriosa, o Siric, pois até então não se fazia uma análise profunda da pessoa que ia tomar o empréstimo. Mas parece que todas essas medidas não surtiram o efeito esperado.

A inadimplência habitacional dos créditos pertencentes à Caixa já chegam a um porcentual de I4\%, e em Pernambuco esse índice é ainda maior, próximo a 20\% (CAIXA ECONÔMICA FEDERAL, 2004).

Explicar esses índices não é uma tarefa fácil, pois envolve vários fatores da economia, como crescimento econômico, taxas de desemprego, perda e concentração de renda.

Para tentar reverter esse quadro de inadimplência, à Caixa criou, a partir de I999, as Gerências de Recuperação de Ativos (Girat), hoje Gerências de Filial de Créditos Próprios (Gipro), já que com a venda de ativos para a Emgea, esta ficou responsável pela cobrança dos créditos de terceiros, por meio das Gerências de Filiais de Créditos de Terceiros (Giter).

As Gipro possuem analistas especializados em cobrança de ativos e em ações e atitudes corretivas na recuperação de créditos inadimplentes. Além disso, coordenam a ação das empresas de cobrança terceirizadas que cobram os contratos.

No âmbito do Estado de Pernambuco, as Gipro atuam na cobrança de duas superintendências regionais, de Recife e Caruaru, sendo responsável pela cobrança de todos os contratos pertencentes a essas bases, da qual não fazem parte os contratos vendidos à Emgea. Teoricamente, são contratos que mantêm um equilíbrio entre o valor da prestação e o saldo devedor, já que quase todos foram assinados pelo sistema de amortização Sacre, que, ao contrário do Price, não deixa resíduo ao final do contrato.

O sistema Sacre foi desenvolvido com o objetivo de permitir maior amortização do valor emprestado, reduzindo-se simultaneamente a parcela de juro sobre o saldo devedor.

A cobrança na Caixa é efetuada da seguinte maneira:

- Até os primeiros 35 dias de atraso, a cobrança é feita pelas agências responsáveis pelo contrato.

- Após 35 dias, para contratos com dívidas até $\mathrm{R} \$ 50$ mil a cobrança é feita por duas empresas de cobrança terceirizada, Exponencial Serviços de Consulto- 
ria e Assessoria Ltda e Jorge \& Lima Assessoria e Consultoria Jurídica Ltda. Para dívidas acima de $\mathrm{R} \$ 50$ mil a cobrança é feita pelas Gipro.

- Caso o contrato, após decorridos 90 dias de disponibilização à empresa terceirizada, não retorne à adimplência, ele retorna à Caixa para as providências de execução e, se necessário, da retomada do imóvel e sua posterior venda em concorrência pública ao interessado que pagar, no mínimo, o seu valor de mercado.

Os contratos em cobrança pertencentes ao banco Caixa, ou seja, créditos próprios, apresentam as seguintes opções de negociação:

- Incorporação de até $80 \%$ do débito em atraso ao saldo devedor, caso o mutuário comprove que teve os imprevistos de perda de renda, desemprego, doença na família, separação ou algum outro fator involuntário comprovado com documentação específica.

- Dilatação de prazo com redução da prestação, caso o contrato não esteja no seu prazo máximo permitido e que esteja em dia com as prestações, tendo o mutuário que comprovar, também, uma das situações previstas no item anterior.

- Pagamento de $70 \%$ do débito em atraso à vista e o restante dividido em $30 \mathrm{e}$ 60 dias, a critério do analista, supervisor ou gerente.

- Uso do FGTS para amortização ou liquidação do saldo devedor, se o contrato assim o prevê e se o mutuário satisfizer as condições básicas para seu uso, ou seja, ter mais de três anos de conta, não ter feito uso para a mesma modalidade nos últimos dois anos, não ser proprietário de outro imóvel e que este esteja localizado no seu local de trabalho ou residência.

Essas opções são oferecidas após o analista realizar um estudo da situação do contrato e de analisar a situação financeira do mutuário, devendo prevalecer o bom senso e o princípio básico de uma negociação, ou seja, que ela seja boa para ambos os lados.

Depois de encerrados os procedimentos de cobrança e execução e não tendo compradores nos dois leilões a que são submetidos, a Caixa arremata os imóveis e coloca à venda pelo preço de mercado ao interessado que pague o valor mínimo estipulado.

Atualmente, a Caixa tem mais de 60 mil imóveis disponíveis na sua página na internet, para consulta de interessados em comprá-los.

Essa quantidade de imóveis acarreta para a instituição um custo de manutenção da ordem de R\$236 milhões ao ano. Desse montante, devem ser con- 
siderados gastos com manutenção do estoque e de oportunidade de aplicação do dinheiro. Essa performance pode ser atribuída à criação, durante I999, das Gerências de Alienação de Bens Móveis e Imóveis (Gilie), que se tornaram responsáveis pela venda dos imóveis retomados por meio de execução. Entre outras atividades, essa gerência é responsável por promover leilões, concorrência pública e venda direta dos imóveis pela página da internet da Caixa ou por meio de convênios firmados com os Conselhos Regionais dos Corretores de Imóveis, impondo uma sistemática profissional às vendas e adaptando o trabalho às práticas de mercado.

\subsection{CAUSAS DA INADIMPLÊNCIA HABITACIONAL NO ESTADO DE PERNAMBUCO}

\section{QUADRO I}

PRINCIPAIS CAUSAS DA INADIMPLENCIA HABITACIONAL NO ESCRITÓRIO DE NEGÓCIOS - EN RECIFE/PE

\begin{tabular}{lc}
\hline CAUSAS & $\%$ \\
\hline Desemprego & 15,45 \\
\hline Perda de renda & 28,39 \\
\hline Doença na família & 17,92 \\
\hline Descontrole financeiro & 25,29 \\
\hline Separação conjugal & 2,74 \\
\hline Outros & 10,21 \\
\hline Total & $\mathbf{1 0 0}$ \\
\hline
\end{tabular}

Fonte: Dados da pesquisa, 2004 .

A perda de renda e o descontrole financeiro são os dois fatores que mais causam inadimplência na região metropolitana do Recife e refletem a situação que se encontra a economia no Brasil, com salários defasados que não acompanham os preços dos produtos e serviços. Doença na família e desemprego também apresentaram porcentuais relevantes. 


\section{QUADRO 2}

PRINCIPAIS CAUSAS DA INADIMPLENCIA HABITACIONAL EN CARUARU/PE

\begin{tabular}{lc}
\hline CAUSAS & $\%$ \\
\hline Desemprego & 17,34 \\
\hline Perda de renda & 15,41 \\
\hline Doença na família & 4,27 \\
\hline Descontrole financeiro & 43,19 \\
\hline Separação conjugal & 3,21 \\
\hline Outros & 16,58 \\
\hline Total & 100 \\
\hline
\end{tabular}

Fonte: Dados da pesquisa, 2004.

No interior, nota-se que o desemprego é o segundo fator que gera mais inadimplência, e o primeiro, assim como na região metropolitana, é o descontrole financeiro, seguido de perto pela perda de renda e doença na família. Esses fatores devem ser criteriosamente analisados porque a Caixa oferece poucas possibilidades de negociação para quem está desempregado, e buscar soluções para essas pessoas é questão de sobrevivência.

Os índices obtidos revelaram que no interior $63,72 \%$ dos mutuários não possuem débitos com outras instituições. Por sua vez, em Recife, 54,28\% afirmaram que não possuem débitos. É importante destacar que existe uma prioridade para os pagamentos de outros débitos, que normalmente têm uma cobrança mais efetiva e cobram juros mais altos. São necessárias ações mais efetivas de cobrança que aumentem as execuções e introjetem nas pessoas a cultura de priorizar o pagamento das prestações habitacionais, fazendo que outras pessoas tenham acesso à moradia.

Observa-se no Quadro 5 que a saúde está em primeiro lugar nas prioridades dos mutuários da capital, em seguida vêm habitação e educação. A habitação não está entre as prioridades quando o orçamento encurta, talvez porque as pessoas considerem que esta é uma obrigação do governo. É importante destacar que por muitos anos foram dadas muitas vantagens para se resolverem débitos pendentes. 
- RAM - REVISTA DE ADMINISTRAÇÃO MACKENZIE •

Volume 8, n. 2, 2007, p. 59-84

\section{QUADRO 3}

DEBITOS PENDENTES COM OUTRAS INSTITUIÇOEE - EN RECIFE/PE

\begin{tabular}{lc}
\hline & $\%$ \\
\hline Sim & 45,72 \\
\hline Não & 54,28 \\
\hline Total & $\mathbf{1 0 0}$ \\
\hline
\end{tabular}

Fonte: Dados da pesquisa 2004.

\section{QUADRO 4}

DEBITOS PENDENTES COM OUTRAS INSTITUIÇOOES - EN CARUARU/PE

\begin{tabular}{lc}
\hline & $\%$ \\
\hline Sim & 36,28 \\
\hline Não & 63,72 \\
\hline Total & $\mathbf{1 0 0}$ \\
\hline
\end{tabular}

Fonte: Dados da pesquisa 2004.

\section{QUADRO 5}

PRIORIDADE NO ORÇAMENTO FAMILIAR - EN RECIFE/PE

\begin{tabular}{lc}
\hline PRIORIDADE & $\%$ \\
\hline Saúde & 45,93 \\
\hline Habitação & 26,65 \\
\hline Educação & 19,43 \\
\hline Lazer & 4,74 \\
\hline Outros & 3,25 \\
\hline Total & 100 \\
\hline
\end{tabular}

Fonte: Dados da pesquisa 2004. 


\section{QUADRO 6}

PRIORIDADE NO ORÇAMENTO FAMILIAR - EN CARUARU/PE

\begin{tabular}{ll}
\hline PRIORIDADE & $\%$ \\
\hline Saúde & 39,84 \\
\hline Habitação & 11,15 \\
\hline Educação & 31,28 \\
\hline Lazer & 7,19 \\
\hline Outros & 10,54 \\
\hline Total & $\mathbf{1 0 0}$ \\
\hline
\end{tabular}

Fonte: Dados da pesquisa 2004.

No interior, observa-se que a saúde também está em primeiro lugar, em seguida vem educação e em terceiro a habitação. Vale ressaltar que em Recife, com um total de $26,65 \%$, a prioridade, no orçamento familiar, com a habitação é bastante superior do que no interior. A análise, dentro de um contexto macro, não muda muito, já que o fato de os financiamentos habitacionais terem sido concedidos muitas vezes por interferências políticas, sem critérios consistentes de concessão, torna o mutuário um candidato natural à inadimplência, e, na hora de priorizar o pagamento de um item do orçamento, este não será a habitação.

\section{QUADRO 7}

INDICE DE LEITURA DO CONTRATO ANTES DA AS SINATURA EN RECIFE/PE

\begin{tabular}{lc}
\hline & $\%$ \\
\hline Sim & 69,21 \\
\hline Não & 30,79 \\
\hline Total & $\mathbf{1 0 0}$ \\
\hline
\end{tabular}

Fonte: Dados da pesquisa 2004 . 


\section{QuAdro 8}

INDICE DE LEITURA DO CONTRATO ANTES DA ASSINATURA EN CARUARU/PE

\begin{tabular}{lc}
\hline & $\%$ \\
\hline Sim & 55,05 \\
\hline Não & 44,95 \\
\hline Total & $\mathbf{1 0 0}$ \\
\hline
\end{tabular}

Fonte: Dados da pesquisa 2004 .

Os dados apresentados nos quadros 7 e 8 mostram que 30,79\% dos mutuários na capital e 44,95\% no interior não leram o contrato antes de assiná-lo. Isso significa que pouco conhecimento sobre condições, taxas de juros e sistema de amortização eles tiveram, dificultando a compreensão da evolução do contrato. Reflete também um pouco do perfil do futuro inadimplente, pois quem procura se informar de todas as condições do contrato está preocupado com a sua evolução durante os anos de financiamento. Na hora da concessão, esses fatos devem ser cuidadosamente analisados.

\section{QuADRO 9}

COMPARATIVO DO COMPROMETIMENTO DE RENDA NA ASSINATURA DO CONTRATO E ATUAL - EN RECIFE/PE

\begin{tabular}{lc}
\hline NÍVEL & $\%$ \\
\hline Baixou & 21,76 \\
\hline Manteve & 22,07 \\
\hline Subiu & 56,17 \\
\hline Total & 100 \\
\hline
\end{tabular}

Fonte: Dados da pesquisa 2004.

Os porcentuais de $56,17 \%$ de contratos da capital e $60,53 \%$ do interior que tiveram aumento no comprometimento da renda refletem o resultado da pergunta 
I, ou seja, muitos mutuários tiveram perda de renda quando da assinatura do contrato até hoje, ou comprometeram no início um porcentual muito grande de sua renda, dificultando os pagamentos atuais e futuros. É um caso a ser pensado se realmente vale a pena conceder um financiamento em que a renda esteja no limite máximo de comprometimento, levando o mutuário, caso tenha um imprevisto, a ser um forte candidato a atrasar seus pagamentos.

\section{QuAdro IO}

COMPARATIVO DO COMPROMETIMENTO DE RENDA NA ASSINATURA DO CONTRATO E ATUAL - EN CARUARU/PE

\begin{tabular}{lc}
\hline NÍVEL & $\%$ \\
\hline Baixou & 27,78 \\
\hline Manteve & 11,69 \\
\hline Subiu & 60,53 \\
\hline Total & $\mathbf{1 0 0}$ \\
\hline
\end{tabular}

Fonte: Dados da pesquisa 2004.

\subsection{ANÁLISE COMPARATIVA}

Esta pesquisa, além de buscar a compreensão do grau de importância dado pelos mutuários da Caixa no que se refere à inadimplência habitacional, também buscou verificar o motivo da diferença de índices (veja a Figura I) de inadimplência verificado, de I9,27\% na capital e $22,44 \%$ no interior. Após a análise das respostas, podem-se inferir as seguintes conclusões:

- Nos quadros 3 e 4, observa-se que 63,72\% dos mutuários do interior responderam que não possuem débitos com outras instituições, contra $54,28 \%$ da capital. Isso mostra que o interior prioriza mais débitos com outras instituições.

- Observa-se nos quadros 5 e 6 que a prioridade no orçamento familiar dos mutuários da capital está na saúde, em seguida vem a habitação com 26,65\%. No interior, a prioridade principal também é saúde, em seguida vem educação e depois habitação com um índice de apenas II,I5\%. 
- Nos quadros 7 e 8, observa-se na capital um índice de 30,79\% de mutuários que não leram o contrato antes da assinatura. No interior, esse índice chega a $44,95 \%$, o que gera uma tendência de, pelo desconhecimento das condições do contrato, haver mais dificuldade na interpretação das suas cláusulas, ocasionando, assim, mais inadimplência.

- Nos quadros 9 e io, observa-se que o índice de comprometimento de renda antes da assinatura e atual, no interior, aumentou. Esse resultado mostra que os mutuários dessa localidade estão tendo mais dificuldades para pagar as prestações em dia.

Com esses índices, torna-se claro o porquê da diferença em torno de 3,00\% na inadimplência da capital e do interior. Além de priorizar numa proporção maior débitos com outras instituições, tem-se plena certeza de que o conhecimento das cláusulas contratuais, como taxas de juros, prazos e sistema de amortização, é muito baixo no interior. Dessa forma, as gerências deverão fornecer toda orientação necessária acerca das regras dos financiamentos, tornar obrigatória a leitura do contrato e esclarecer eventuais dúvidas que surgirem.

\section{CONSIDERAÇÕES FINAIS}

Após a realização da pesquisa, observou-se que existe uma certa angústia e ansiedade por parte das pessoas que adquirem seus imóveis por meio de financiamentos habitacionais. Elas estão diretamente ligadas à necessidade de comprar o imóvel e ter que se submeter às regras estipuladas pelo Sistema Financeiro Nacional (SFN). Por isso, de acordo com os resultados obtidos neste estudo, ficou demonstrado que podem ser explicitadas algumas recomendações:

- É necessário e urgente que se reavaliem as taxas de juros praticadas pelos bancos.

- É importante exigir das instituições financeiras um simulador de financiamentos de longo prazo, como é o habitacional. Dessa forma, a pessoa que esteja tomando o empréstimo poderá fazer algumas simulações e escolher a melhor forma de financiar, decidindo, com base nesse conhecimento, sobre o sistema de amortização a ser utilizado, seus prazos e formas de pagamento.

- Tornar possível e disponível aos mutuários de empréstimos habitacionais taxas de juros que possam ser negociadas de acordo com o prazo de amortização a ser utilizado. 
- Tornar o segmento habitacional uma política pública, em que haja, inclusive, emendas dentro do Orçamento Geral da União (OGU), com vistas a custear ou subsidiar linhas de crédito habitacional voltadas à classe de menor renda, a exemplo do que se pratica com os recursos do FGTS.

- Criar opções de negociação para mutuários que se encontram em dificuldades financeiras, os quais, por perda de poder aquisitivo, deixam de pagar suas prestações. Como a prestação não se vincula mais ao salário, havendo desemprego ou perda de renda, torna-se difícil continuar pagando a prestação.

- Instituir o seguro de crédito que venha a cobrir, por tempo limitado, a prestação habitacional, o qual deverá ser opcional. Caso o mutuário opte por esse seguro, ele será agregado ao valor da prestação.

A maior contribuição do presente estudo para o dia-a-dia da Caixa é incentivar a busca pelo conhecimento e alertar para as dificuldades que podem ser originadas, a partir de créditos concedidos e não pagos. A falta dos pagamentos gera um descasamento no fluxo de caixa das empresas e leva muitas delas à falência, trazendo conseqüências como o desemprego e desajuste social nas famílias diretamente envolvidas no processo.

É importante deixar claro que, independentemente do lado em que o indivíduo estiver, deve estar atento às peculiaridades que envolvem a sua atividade e, também, à conjuntura econômica que o País atravessa, como também trabalhar cenários atuais e futuros que podem minimizar riscos e reduzir os possíveis impactos negativos, mais tarde.

Para a Caixa, acredita-se que, com base nas informações disponibilizadas, ela possa rever a sua política pós-concessão do crédito, o chamado pós-venda, para que, tempestivamente, detecte o crédito problemático e atue, rapidamente, em busca da recuperação desse ativo, de forma a manter o equilíbrio financeiro da empresa, possibilitando novos empréstimos. Treinar os gerentes para transformá-los em consultores, que orientem qual a melhor alternativa e linha de crédito adequada ao seu cliente, com o objetivo de que ele não se torne um inadimplente no futuro.

É importante buscar cada vez mais simplificar os processos de concessão de financiamento imobiliário. Também é imprescindível esclarecer à população quais as formas de acesso ao financiamento habitacional, evitando, assim, que as pessoas mais humildes se submetam a despachantes que cobram para encaminhar os documentos à Caixa. Se essas medidas forem adotadas, a população poderá obter as informações necessárias e desvencilhar-se de armadilhas futuras. O financiamento habitacional foi feito para facilitar o acesso da população à casa própria e não pode representar um pesadelo na vida dessas pessoas. 


\section{REFERÊNCIAS}

BLATT, Adriano. Créditos problemáticos e inadimplência. São Paulo: STS, I998.

CAIXA ECONÔMICA FEDERAL. Edições do Boletim da Caixa. Disponível em: <http://www.caixa>. Acesso em: 27 set. 2004.

FONSECA, Jairo Simon da; MARTINS, Gilberto de Andrade. Curso de estatística. 6. ed. São Paulo: Atlas, I996.

GIL, Antônio Carlos. Como elaborar projetos de pesquisa. São Paulo: Atlas, I99I.

GITMAN, Lawrence J. Princípios de administração financeira. 7. ed. São Paulo: Harbra, 2002.

MARTINS, Venevaldo Almeida. O déficit habitacional e as políticas federais de habitação no Brasil. São Paulo: Atlas, I998.

MORAIS, Maria Piedade. Setor habitacional, nova política habitacional. Paraná: Finatec, Ipea, World Bank, Sedu/PR, 200I.

RAMPAZZO, Lino. Metodologia científica para alunos dos cursos de graduação e pós-graduação. São Paulo: Edições Loyola, 2002.

RICHARDSON, Roberto Jarry. Pesquisa social: métodos e técnicas. São Paulo: Atlas, I999.

ROCHA, Antonio Carlos. Na selva do calote concedendo e recuperando créditos. São Paulo: Futura, I997. SILVA, José Pereira da. Gestão e análise de risco de crédito. São Paulo: Atlas, I997.

\section{TRAMITAÇÃO}

Recebido em 4/8/2005

Aprovado em 14/10/2006 


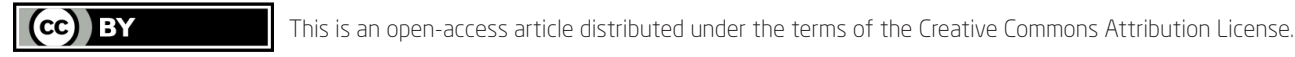

This paper may be copied, distributed, displayed, transmitted or adapted if provided, in a clear and explicit way, the name of the journal, the edition, the year and the pages on which the paper was originally published, but not suggesting that RAM endorses paper reuse. This licensing term should be made explicit in cases of reuse or distribution to third parties. It is not allowed the use for commercial purposes.

Este artigo pode ser copiado, distribuído, exibido, transmitido ou adaptado desde que citados, de forma clara e explícita, o nome da revista, a edição, o ano e as páginas nas quais o artigo foi publicado originalmente, mas sem sugerir que a RAM endosse a reutilização do artigo. Esse termo de licenciamento deve ser explicitado para os casos de reutilização ou distribuição para terceiros. Não é permitido o uso para fins comerciais. 